\title{
Factors affecting the occurrence of postpartum depression among puerperal women in Sohag city, Egypt.
}

\author{
Mohammed N. Salem,MD, ${ }^{1}$ Mohamed N. Thabet, MD, ${ }^{2}$ Howieda Fouly, PhD, ${ }^{3}$ Ahmed \\ M. Abbas, $\mathrm{MD}^{4}$
}

Keywords: Postpartum depression, puerperium, maternal morbidity.

\begin{abstract}
Aim: Postpartum Depression (PPD) is one of the most common complications of the postpartum period. In Egypt, previous studies have reported that the prevalence of PPD ranged from $20-50 \%$ depending on location in Lower and Upper Egypt. This study aimed to evaluate the cofactors affecting the occurrence of PPD amongst puerperal women in Sohag city, Egypt.

Methods: The study was carried out at Sohag University Hospital from June 2015 to May 2016. All women within 6 weeks after birth who gave their consent were included. A pretested questionnaire including demographic, psychosocial, maternal and infant variables as well as the Edinburgh Postnatal Depression Scale (EPDS) was completed. A woman with an $E P D S$ score $\geq 13$ was considered to have $P P D$, while a score $<12$ ruled out $P P D$.

Results: We recruited 658 women, among whom 47 had an EPDS score $\geq 13$, giving a prevalence of $7.14 \%$ of PPD. Women who delivered female babies or those who had a medical illness in their babies were significantly more likely to suffer from PPD.
\end{abstract}

Conclusion: The prevalence of PPD in our setting was $7.14 \%$ which reflected the lowest prevalence among regions in Egypt. This could be due to differences of regional culture, families' ties or other co-factors and needs further verification.

${ }^{1}$ Department of Obstetrics \& Gynecology, Faculty of Medicine, Sohag, Egypt

${ }^{2}$ Department of Neuropsychiatry. Faculty of Medicine, Sohag, Egypt

${ }^{3}$ Department of Obstetrics \& Gynecology of Nursing, Faculty of Nursing, Assiut University, Egypt

${ }^{4}$ Department of Obstetrics \& Gynecology, Faculty of Medicine, Assiut University, Egypt

\section{Introduction}

The event of becoming a mother is associated with emotional disturbance in about thirty percentage of women. ${ }^{1,2}$ Therefore, biological changes during pregnancy and childbirth along with sociocultural factors may precipitate the development of post-partum depression (PPD) ${ }^{3}$. Not only the hormonal changes during or after pregnancy are responsible for the PPD, but it is also found in the mothers with lower socio

Please cite this paper as: Salem MN, Thabet MN, Fouly $H$, Abbas AM. Factors affecting the occurrence of postpartum depression among puerperal women in Sohag city, Egypt. Proc Obstet Gynecol. 2017;7(1): Article 4 [ 10 p.]. Available from: http://ir.uiowa.edu/pog/ Free full text article.

Corresponding author: Ahmed M. Abbas, MD, Department of Obstetrics and Gynecology, Faculty of Medicine; Assiut University, Assiut, Egypt; Woman's Health Hospital, 71511, Assiut, Egypt, Cellular: +20 10033851833; Tel: +2088 2414616; email: bmr90@hotmail.com

Financial Disclosure: The authors report no conflict of interest.

Copyright: (C) 2017 Salem et al. This is an open-access article distributed under the terms of the Creative Commons Attribution License, which permits unrestricted use, distribution, and reproduction in any medium, provided the original author and source are credited. 
economic status, poor interpersonal relationships and mothers with less social support. ${ }^{4}$ Also, Milgrom et al., 2008 reported that antenatal depression and low partner support aggravate PPD. ${ }^{5}$ Postpartum depression is characterized by a non-psychotic depressive episode of mild, moderate or severity, beginning in or extending into the first postnatal year. ${ }^{6}$

Previous studies reported that the etiological factors of PPD that new mothers commonly experience are interpersonal stress and baby gender issues. ${ }^{7}$ Thus, many dissimilar cultural settings have been reported. A phenomenological study showed that Australian women with PPD suffered from painful emotions and guilt, and experienced a dual reality. ${ }^{3}$ The majority of the studies on PPD have been conducted in Western countries, with only a few recent studies conducted in developing countries.

The lack of research on psychological morbidities in developing countries has led to a gap in assessing the global burden of the disease. ${ }^{3}$ Therefore, the prevalence is estimated between 10\% and $20 \%$, with an average prevalence of $13 \% .{ }^{8}$ This is determined by the geographic location and the socioeconomic conditions. In Egypt, studies have reported a prevalence in Gharbia Governorate of $20 \%{ }^{9}$. In the El-Minia study, 20\% had major PPD and $29.5 \%$ had minor PPD, ${ }^{10}$ and in Mansoura it was $17.9 \%{ }^{11}$. However, in the Assiut study, the prevalence confirmed the major prevalence of $51.7 \% .{ }^{12}$

Healthcare professionals "physicians, nurses and midwives" play an important role in developing culturally and provide appropriate interventions which help mothers to anticipate the demands of childcare. For example, women should be reassured that failure to breastfeed does not mean failing as a mother. In addition, to assist women to identify interpersonal difficulties and to improve their capacity to handle relationship issues would also be useful. Husbands and family members could be invited to sessions, at which staff could discuss whether a more flexible approach to participation in traditional rituals is possible. ${ }^{14}$

The Edinburgh postnatal depression scale was initially developed as a screening tool and focuses on the cognitive and functional effects of depression to facilitate detection of women with postnatal depression in the months immediately postpartum. ${ }^{15}$ Although it is not a diagnostic tool, a score above 13 is predictive of PPD.

The aim of our study was to evaluate the co-factors affecting the occurrence of PPD amongst puerperal women in Sohag city, Egypt.

\section{Methods}

This was a cross-sectional study conducted at the Family Planning Outpatient Clinic in Sohag University Hospital between June 2015 till May 2016. The hospital is a large tertiary care hospital in Upper Egypt with more than 10,000 deliveries annually. It provides the health services to all women in the city and the surrounding semi-urban areas and villages. The ethical review board of the Faculty of Medicine of Sohag University approved 
the study.

All women within 6 weeks postpartum attending the clinic asking for contraception during this period were invited to participate in our study. An informed written consent was obtained before participation.

The inclusion criteria were: age 20-35 years, women who delivered a single living term fetus whether vaginally or by cesarean section (CS). We excluded those with multiple pregnancies, stillbirths, previously diagnosed fetal anomalies, pregnancy after assisted reproduction, medical diseases, and assisted vaginal delivery (ventose or forceps).

One of the study investigators collected the sociodemographic data including: age, parity, religion, socioeconomic status, working status, marital status, educational level, delivery data as mode of delivery, occurrence of postpartum complications, episiotomy, newborn sex and health problems. Then the women were interviewed face to face to fill out the Arabic version of the Edinburgh Postnatal Depression Scale (EPDS) which includes 10 inventory questions that investigate their feelings within the previous seven days with four possible answers scored from 0 to 3 . A cut off level of 13 is considered positive and has been used to determine women at risk of postpartum depression.

The Arabic version of the EPDS which was validated by Ghubash et al., $1997^{15}$ the first authors to translate the EPDS into the Arabic language, stated that EPDS had a Cronbach's coefficient of 0.84. The EPDS is a reliable and validated screening tool for PPD developed and has been translated and validated into 57 languages, including Arabic. ${ }^{16}$ The tool was originally designed to be self-administered, but studies have shown that screening through directed interviews is an equivalent screening technique. ${ }^{17}$

The depression tendency of the participants was assessed by EPDS questionnaire and scores of $13+$ require further assessment and appropriate management as the likelihood of depression is high. Referral to a psychiatrist/psychologist may be necessary. Scores 10-12 indicate the presence of symptoms of distress that may be discomforting. Scores $\leq 9$ indicate the presence of symptoms of distress that may be short lived and are less likely to interfere with the day to day ability to function at home or at work

The data were collected and statistically analyzed using a personal computer equipped with statistical package for the social sciences (SPSS; SPSS Inc., Chicago, Illinois, USA) version 20. Descriptive data analysis for demographic variables was expressed as mean and standard deviation for continuous variables and percentages for categorical variables. Patient characteristics were analyzed against EPDS scores by Chi square test. Results were considered significant at $\mathrm{P}$ $<0.05$.

\section{Results}

A total of 723 women were approached to participate in the study. Of these, 27 women refused and 696 agreed to continue the study. Thirty-eight women 
were excluded due to the presence of one or more factors from the exclusion criteria. The included 658 women were classified into two groups according to the results of EDPS; Group (A); those with EPDS $\geq 13$ (with depression, $n=47$ ), and Group (B); those with EPDS < 12 (without depression, $\mathrm{n}=611$ ).

The sociodemographic data of the study participants are summarized in Table 1. There was a statistical significant difference between both groups regarding the marital status $(p=0.001)$, educational status $(p=0.03)$ and socioeconomic levels $(p=0.02)$. On the other hand, both groups are quite similar regarding age, parity, working status and religion.

Table 1: The sociodemographic criteria of the study participants.

\begin{tabular}{|c|c|c|c|}
\hline & $\begin{array}{c}\text { Group (A) } \\
n=47\end{array}$ & $\begin{array}{c}\text { Group (B) } \\
n=611\end{array}$ & p-value \\
\hline $\begin{array}{l}\text { Age (years): } \\
\leq 25 \\
>25\end{array}$ & $\begin{array}{c}39(83 \%) \\
8(17 \%)\end{array}$ & $\begin{array}{l}477(78.1 \%) \\
134(21.9 \%)\end{array}$ & 0.125 \\
\hline $\begin{array}{l}\text { Parity: } \\
\frac{\leq 3}{>3}\end{array}$ & $\begin{array}{l}35(74.4 \%) \\
12(25.6 \%)\end{array}$ & $\begin{array}{l}395 \text { (64.6 \%) } \\
216(35.4 \%)\end{array}$ & 0.61 \\
\hline $\begin{array}{l}\text { Marital status: } \\
\text { Married } \\
\text { Divorced }^{\text {a }} \\
\text { Widow }^{\text {b }}\end{array}$ & $\begin{array}{l}29(61.7 \%) \\
11(23.4 \%) \\
7(14.9 \%)\end{array}$ & $\begin{array}{c}610(99.94 \%) \\
1(0.06 \%) \\
0\end{array}$ & $0.001 *$ \\
\hline $\begin{array}{l}\text { Working status: } \\
\text { Employer } \\
\text { Housewife }\end{array}$ & $\begin{array}{l}22(46.8 \%) \\
25(53.2 \%)\end{array}$ & $\begin{array}{l}287 \text { (47.1 \%) } \\
324 \text { (52.9 \%) }\end{array}$ & 0.164 \\
\hline $\begin{array}{l}\text { Level of education: } \\
\text { Illiterate } \\
\text { Read and write } \\
\text { Primary } \\
\text { Secondary } \\
\text { University }\end{array}$ & $\begin{array}{c}26(55.3 \%) \\
8(17 \%) \\
7(14.9 \%) \\
4(8.5 \%) \\
2(4.3 \%)\end{array}$ & $\begin{array}{c}141(23.1 \%) \\
123(20.1 \%) \\
99(16.2 \%) \\
13(2.1 \%) \\
235(38.5 \%)\end{array}$ & $0.03^{*}$ \\
\hline $\begin{array}{l}\text { Religion: } \\
\text { Muslims } \\
\text { Christians }\end{array}$ & $\begin{array}{l}26(55.3 \%) \\
21(44.7 \%)\end{array}$ & $\begin{array}{l}367 \text { (60.1 \%) } \\
244 \text { (39.9 \%) }\end{array}$ & 0.271 \\
\hline $\begin{array}{l}\text { Socioeconomic status: } \\
\text { Low } \\
\text { Medium } \\
\text { High }\end{array}$ & $\begin{array}{c}33(70.2 \%) \\
13(27.7 \%) \\
1(2.1 \%) \\
\end{array}$ & $\begin{array}{c}404(66.1 \%) \\
93(15.2 \%) \\
114(18.7 \%) \\
\end{array}$ & $0.02 *$ \\
\hline
\end{tabular}

*Statistically significant difference

Group (A); women with EPDS $\geq 13$ (PPD group), Group (B); women with EPDS $<12$ (normal group)

${ }^{a}$ women who were divorced during pregnancy ${ }^{b}$ women's husband dies during her pregnancy 
Table 2 shows the obstetrical data of the study participants. There was a higher incidence of unplanned pregnancy in the PPD group (87.7\%) than the normal group (15.7\%) with a statistical significant difference $(p=0.001)$. Also, there was a statistical significant difference between both groups as regard to the mode of delivery; women who delivered by CS had significantly higher EDPS scores $(p=0.042)$.

Table 2: The obstetrical data of the study participants.

\begin{tabular}{|c|c|c|c|}
\hline & $\begin{array}{c}\text { Group (A) } \\
\mathrm{n}=47\end{array}$ & $\begin{array}{c}\text { Group (B) } \\
n=611\end{array}$ & p-value \\
\hline \multicolumn{4}{|l|}{ Birth order: } \\
\hline Primigravida & 17 (36.2 \%) & 245 (40.1 \%) & \multirow{4}{*}{0.283} \\
\hline Second & $22(46.8 \%)$ & 271 (44.4 \%) & \\
\hline Third & 5 (10.6 \%) & $60(9.8 \%)$ & \\
\hline Multigravida & $3(6.4 \%)$ & $35(5.7 \%)$ & \\
\hline \multicolumn{4}{|l|}{ Current pregnancy: } \\
\hline Planned & $10(21.3 \%)$ & $515(84.3 \%)$ & \multirow[t]{2}{*}{$0.001^{*}$} \\
\hline Unplanned & $37(78.7 \%)$ & $96(15.7 \%)$ & \\
\hline \multicolumn{4}{|l|}{ Mode of delivery: } \\
\hline Vaginal & $12(25.5 \%)$ & 320 (52.4 \%) & \multirow[b]{2}{*}{$0.042 *$} \\
\hline CS & $35(74.5 \%)$ & $291(47.6 \%)$ & \\
\hline \multicolumn{4}{|l|}{ Pregnancy duration: } \\
\hline Preterm & $6(12.8 \%)$ & $91(14.9 \%)$ & \multirow{3}{*}{0.192} \\
\hline Term & $32(68.1 \%)$ & $405(66.3 \%)$ & \\
\hline Post-term & $9(19.1 \%)$ & 115 (18.8 \%) & \\
\hline \multicolumn{4}{|l|}{ Hospital readmission: } \\
\hline Yes & $5(10.6 \%)$ & 79 (13 \%) & \multirow[t]{2}{*}{0.42} \\
\hline No & $42(89.4 \%)$ & 532 (87 \%) & \\
\hline \multicolumn{4}{|l|}{ Postpartum hemorrhage: } \\
\hline$\overline{\text { Yes }}$ & $3(6.4 \%)$ & 23 (3.8 \%) & \multirow[t]{2}{*}{0.331} \\
\hline No & $44(93.6 \%)$ & $588(96.2 \%)$ & \\
\hline
\end{tabular}

*Statistically significant difference

Group (A); women with EPDS $\geq 13$ (PPD group), Group (B); women with EPDS $<12$ (normal group)

Table 3 shows that women who delivered female babies and those who had a medical illness in their babies suffered significantly from PPD $(p<0.001)$. There was no difference between both groups in regard to the 
postpartum initiation of lactation.

Table 4 shows no significant difference in the rate of PPD between those who had poor marital relationships, poor social support, previous history of PPD and bad general health or not.

Table 3: The newborn characteristics of the study participants.

\begin{tabular}{lccc}
\hline & $\begin{array}{c}\text { Group (A) } \\
\mathbf{n = 4 7}\end{array}$ & $\begin{array}{c}\text { Group (B) } \\
\mathbf{n}=611\end{array}$ & p-value \\
\hline Infant gender: & $13(27.7 \%)$ & $300(49.1 \%)$ & $0.001^{*}$ \\
Boy & $34(72.3 \%)$ & $311(50.9 \%)$ & \\
Immediate postpartum lactation: & & & \\
\hline Yes & $24(51.1 \%)$ & $357(58.5 \%)$ & 0.155 \\
No & $23(48.9 \%)$ & $254(41.5 \%)$ & \\
Newborn medical illness: & & & \\
\hline Yes & $41(87.2 \%)$ & $323(52.9 \%)$ & $0.006^{*}$ \\
No & $6(12.8 \%)$ & $288(47.1 \%)$ & \\
\hline
\end{tabular}

*Statistically significant difference

Group (A); women with EPDS $\geq 13$ (PPD group), Group (B); women with EPDS $<12$ (normal group)

Table 4: Co-factors of PPD among the study groups.

\begin{tabular}{|l|c|c|c|}
\hline Co-factors & $\begin{array}{c}\text { Group (A) } \\
\mathbf{n = 4 7}\end{array}$ & $\begin{array}{c}\text { Group (B) } \\
\mathbf{n = 6 1 1}\end{array}$ & p-value \\
\hline Postpartum health: & $9(19.1 \%)$ & $134(21.9 \%)$ & \\
Good & $17(36.2 \%)$ & $195(31.9 \%)$ & 0.412 \\
Fair & $21(44.7 \%)$ & $282(46.2 \%)$ & \\
Social support: & & & \\
Yes & $24(51.1 \%)$ & $287(46.9 \%)$ & 0.281 \\
No & $23(48.9 \%)$ & $324(53.1 \%)$ & \\
Poor marital relationship: & $22(46.8 \%)$ & $324(53 \%)$ & 0.331 \\
Yes & $25(53.2 \%)$ & $287(47 \%)$ & \\
No & & & \\
Previous history of PPD: & $13(27.7 \%)$ & $135(22.1 \%)$ & 0.544 \\
\hline
\end{tabular}


Proceedings in Obstetrics and Gynecology, 2017;7(1):4

\begin{tabular}{|l|l|l|l|}
\hline No & $34(72.3 \%)$ & $476(77.9 \%)$ & \\
\hline
\end{tabular}

Group (A); women with EPDS $\geq 13$ (PPD group), Group (B); women with EPDS $<12$ (normal group)

Discussion

Postpartum women across different cultures and socioeconomic backgrounds are highly susceptible for PPD from six to eight weeks. ${ }^{18}$ In the current study, the overall prevalence of PPD was $7.32 \%$. This coincides with the range of prevalence reported in Asian countries which indicated the prevalence of PPD fluctuated from 3.5\% to $63.3 \%$. $^{19}$

However, the other locations in Egypt reflected different prevalence as the Gharbia Governorate ${ }^{9}$ and El-Minia ${ }^{10}$ studies reflected a higher prevalence reaching $20 \%$, and the same $20 \%$ for major PPD and 29.5\% had minor PPD. In the Mansoura study ${ }^{11}$ also was close to these prevalence $17.9 \%$. However, in the Assiut study ${ }^{12}$ the prevalence was the majority percentage,51.7\%. These differences may be due the point in time applied, different cut off points of the same tool and other cultural issues. ${ }^{20}$ Additionally, this could be explained by the different population size and method of sampling.

In accord with other studies, ${ }^{21-23}$ our study did not find an association between age and PPD. However, the prevalence of PPD was high among women less than 25 years old which is similar to a study by Zagade and Deshpande in 2013 where they observed that PPD was more prevalent among the $21-25$ age group. ${ }^{24}$

In our study, parity was not found to be a co-factor for development of PPD, in contrast to a study done in India which confirmed that multiparity acts as an additional burden for the postpartum women as she has to supply, not only to the needs of the newborn but also look after her other children. ${ }^{25}$ For mode of delivery, otherwise spontaneous vaginal and CS confirmed a statistical significant difference for both modes at $p$ value $=0.042$. This finding was in contrast to a study by Adama et al., 2015 which confirmed that the same factor not considered as co-factor for PPD due to a non-significant relationship between type of childbirth and PPD. ${ }^{26}$

Our study confirmed the idea that the level of education is a contributing factor for postpartum depression taking into consideration that the PPD prevalence is highest in highly educated women that might be related to their life style and involvement in different works and jobs. Our finding contradicts Mohammed et al., $2014^{10}$ and Zagade \& Deshpande, $2013^{24}$ studies in which they observed that the prevalence of PPD among high school educated mothers was more than other educational levels.

An association between socioeconomic status and postpartum depression has been reported in our study, more women in the group A (PPD) had a low socioeconomic status with poor income. Financial problems may act as additional distressing factors. Mohammed et al., 2014 reported that socioeconomic status was significantly correlated with PPD $(p=0.001)$ and can be considered as one of the most 
important factors. ${ }^{10}$ Also, this finding was consistent with the Stewart et al., $2010^{27}$ study which highlighted the importance of social factors, especially poverty, as a risk factor for PPD.

An association between the two groups of participants regarding their infant criteria confirmed a statistically significant difference related to the infant's gender otherwise boy or girl at $p$-value $=0.001$. Similarly, the finding reported by Saleh et al., 2013 ${ }^{11}$ confirmed that PPD patients have a significant difference $(p=0.001)$. This similarity is due to the same Egyptian culture of social belief about superiority of males than females. Also matching with Asian studies which suggested that spousal disappointment with the sex of the baby, specifically if the baby was a girl, was significantly associated with evolving PPD. ${ }^{28,29}$ On the opposite side, Zagade and Deshpande, 2013 ${ }^{24}$ confirmed that no difference was seen between gender of the infant and PPD.

\section{Conclusions}

In conclusion, our study stated the prevalence of PPD in our setting was $7.32 \%$ which reflected the lowest prevalence amongst the corresponding rate of other regions in Egypt. This could be due to differences of regional culture, families' ties or other co-factors that need further verification.

\section{References}

1. Kakyo TA, Muliira JK, Mbalinda SN, Kizza IB, Muliira RS. Factors associated with depressive symptoms among postpartum mothers in a rural district in Uganda. $\quad$ Midwifery. 2012 Jun;28(3):374-9.

https://doi.org/10.1016/j.midw.2011.05.0 01 PubMed PMID: 21601966.

2. Bener A, Gerber LM, Sheikh J. Prevalence of psychiatric disorders and associated risk factors in women during their postpartum period: a major public health problem and global comparison. Int J Womens Health. 2012;4:191-200. https://doi.org/10.2147/IJWH.S29380

PubMed PMID: 22654524; PubMed Central PMCID: PMC3363135.

3. Chan SW, Williamson V, McCutcheon $\mathrm{H}$. A comparative study of the experiences of a group of Hong Kong Chinese and Australian women diagnosed with postnatal depression. Perspect Psychiatr Care. 2009 Apr;45(2):108-18. https://doi.org/10.1111/j.17446163.2009.00211.x PubMed PMID: 19366421.

4. Khooharo Y, Majeed T, Das C, Majeed N, Majeed N, Choudhry AM. Associated risk factors for postpartum depression presenting at a teaching hospital. Annals of King Edward Medical University. 2010 Apr-Jun;16(2):87-90.

5. Milgrom J, Gemmill AW, Bilszta JL, Hayes B, Barnett B, Brooks J, Ericksen $\mathrm{J}$, Ellwood D, Buist A. Antenatal risk factors for postnatal depression: a large prospective study. J Affect Disord. 2008 May;108(1-2):147-57.

https://doi.org/10.1016/j.jad.2007.10.014 PubMed PMID: 18067974.

6. Beck CT. Postpartum depression: it isn't just the blues. Am J Nurs. 2006 May;106(5):40-50; quiz 50-1. https://doi.org/10.1097/00000446200605000-00020 PubMed PMID: 16639243. 
7. Gao LL, Chan SW, Mao Q. Depression, perceived stress, and social support among first-time Chinese mothers and fathers in the postpartum period. Res Nurs Health. 2009 Feb;32(1):50-8. https://doi.org/10.1002/nur.20306

PubMed PMID: 18980171.

8. Motzfeldt I, Andreasen S, Pedersen AL, Pedersen ML. Prevalence of postpartum depression in Nuuk, Greenland--a cross-sectional study using Edinburgh Postnatal Depression Scale. Int J Circumpolar Health. 2013 Aug 5;72. https://doi.org/10.3402/ijch.v72i0.21114 PubMed PMID: 23984294; PubMed Central PMCID: PMC3753142.

9. Nabil RM, Ragab AZ, El Bahy MS, Zeina MA. Psychiatric disorders in the postpartum period. Menoufia Med J. 2015;28:565-70.

https://doi.org/10.4103/1110$\underline{2098.163919}$

10. Mohammed ES, Mosalem FA, Mahfouz EM, Abd ElHameed MA. Predictors of postpartum depression among rural women in Minia, Egypt: an epidemiological study. Public Health. 2014 Sep;128(9):817-24. https://doi.org/10.1016/i.puhe.2014.06.0 06 PubMed PMID: 25213100.

11. Saleh el-S, El-Bahei W, Del El-Hadidy MA, Zayed A. Predictors of postpartum depression in a sample of Egyptian women. Neuropsychiatr Dis Treat. 2013;9:15-24.

https://doi.org/10.2147/NDT.S37156

PubMed PMID: 23293523; PubMed Central PMCID: PMC3533691.

12. Mohamed AN, Mahmoud GA, Said NA, Abdelhafez HA, Maklof AM. Postpartum depression: prevalence and predictors among women at El Eman's Specialized Hospital. Journal of American Science. 2011;7(12):122-8.

http://doi:10.7537/marsjas071211.17
13. Gao LL, Chan SW, You L, Li X. Experiences of postpartum depression among first-time mothers in mainland China. J Adv Nurs. 2010 Feb;66(2):303$12 . \quad$ https://doi.org/10.1111/j.13652648.2009.05169.x PubMed PMID: 20423413.

14. Cox JL, Holden JM, Sagovsky R. Detection of postnatal depression. Development of the 10-item Edinburgh Postnatal Depression Scale. $\mathrm{Br} \mathrm{J}$ Psychiatry. $1987 \quad$ Jun;150:782-6. https://doi.org/10.1192/bjp.150.6.782 PubMed PMID: 3651732.

15. Ghubash R, Abou-Saleh MT. Postpartum psychiatric illness in Arab culture: prevalence and psychosocial correlates. $\mathrm{Br} \mathrm{J}$ Psychiatry. 1997 Jul;171:65-8. https://doi.org/10.1192/bjp.171.1.65 PubMed PMID: 9328498.

16. Cox J, Holden J, Henshaw C. Perinatal mental health: The Edinburg postnatal depression scale (EPDS) manual. $2^{\text {nd }}$ ed. RCPsych Publications; 2014.

17. Kaminsky LM, Carlo J, Muench MV, Nath C, Harrigan JT, Canterino J. Screening for postpartum depression with the Edinburgh Postnatal Depression Scale in an indigent population: does a directed interview improve detection rates compared with the standard self-completed questionnaire? J Matern Fetal Neonatal Med. $2008 \quad$ May;21(5):321-5. https://doi.org/10.1080/1476705080199 5084 PubMed PMID: 18446659.

18. Khalifa DS, Glavin K, Bjertness E, Lien L. Determinants of postnatal depression in Sudanese women at 3 months postpartum: a cross-sectional study. BMJ Open. 2016 Mar 10;6(3):e009443. https://doi.org/10.1136/bmjopen-2015009443 PubMed PMID: 26966055; PubMed Central PMCID: PMC4800153. 
19. Klainin P, Arthur DG. Postpartum depression in Asian cultures: a literature review. Int J Nurs Stud. 2009 Oct;46(10):1355-73. https://doi.org/10.1016/j.ijnurstu.2009.02 .012 PubMed PMID: 19327773.

20. Al Dallal FH, Grant IN. Postnatal depression among Bahraini women: prevalence of symptoms and psychosocial risk factors. East Mediterr Health J. 2012 May;18(5):439-45. PubMed PMID: 22764429.

21. McMahon CA, Boivin J, Gibson FL, Hammarberg K, Wynter K, Saunders D, Fisher J. Age at first birth, mode of conception and psychological wellbeing in pregnancy: findings from the parental age and transition to parenthood Australia (PATPA) study. Hum Reprod. 2011 Jun;26(6):1389-98. https://doi.org/10.1093/humrep/der076

PubMed PMID: 21441544.

22. Smith LE, Howard KS. Continuity of paternal social support and depressive symptoms among new mothers. J Fam Psychol. $2008 \quad$ Oct;22(5):763-73. https://doi.org/10.1037/a0013581

PubMed PMID: 18855512; PubMed Central PMCID: PMC2597799.

23. Clout D, Brown R. Sociodemographic, pregnancy, obstetric, and postnatal predictors of postpartum stress, anxiety and depression in new mothers. J Affect Disord. 2015 Dec 1;188:60-7. https://doi.org/10.1016/j.jad.2015.08.054 PubMed PMID: 26342890.

24. Zagade TB, Deshpande P. A study to assess the level of postnatal depression among postnatal mothers admitted in the Krishna Hospital, Karad. International Journal of Science and Research (IJSR). 2015 Apr;4(4): 85-90.
25. Hegde S, Latha KS, Bhat SM, Sharma PSVN, Kamath A, Shetty AK. Postpartum Depression: Prevalence and Associated Factors among Women in India. J Womens Health, Issues Care. 2012;1:1. http://doi:10.4172/2325$\underline{9795.1000101}$

26. Adama D, Foumane N, Kamga Olen $P$, Sama Dohbit JP, Ngo Um Meka J, Mboudou E. Prevalence and risk factors of postpartum depression in Yaounde, Cameroon. Open J Obstet Gynecol. 2015;5:608-17. https://doi.org/10.4236/ojog.2015.51108 $\underline{6}$

27. Stewart RC, Bunn J, Vokhiwa M, Umar E, Kauye F, Fitzgerald M, Tomenson B, Rahman A, Creed F. Common mental disorder and associated factors amongst women with young infants in rural Malawi. Soc Psychiatry Psychiatr Epidemiol. $2010 \quad$ May;45(5):551-9. https://doi.org/10.1007/s00127-0090094-5 PubMed PMID: 19609476.

28. Patel V, Rodrigues M, DeSouza N. Gender, poverty, and postnatal depression: a study of mothers in Goa, India. Am J Psychiatry. 2002 Jan;159(1):43-7.

https://doi.org/10.1176/appi.ajp.159.1.43 PubMed PMID: 11772688.

29. Lee DT, Yip AS, Leung TY, Chung TK. Identifying women at risk of postnatal depression: prospective longitudinal study. Hong Kong Med J. 2000 Dec;6(4):349-54. PubMed PMID: 11177155. 